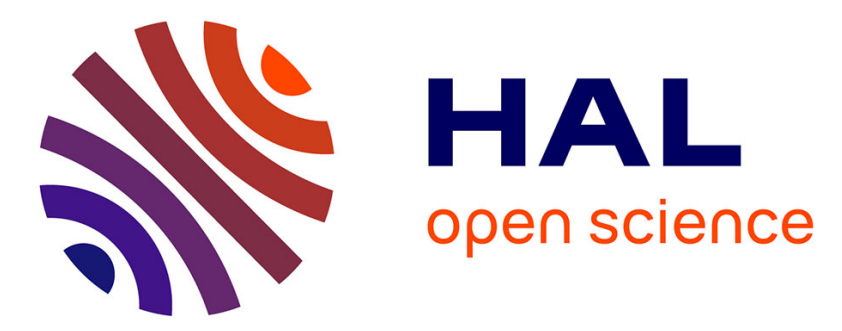

\title{
Do Deep Eutectic Solvents Form Uniform Mixtures Beyond Molecular Microheterogeneities?
}

Lucie Percevault, Aicha Jani, Thibaut Sohier, Laurence Noirez, Ludovic Paquin, Fabienne Gauffre, Denis Morineau

\section{- To cite this version:}

Lucie Percevault, Aicha Jani, Thibaut Sohier, Laurence Noirez, Ludovic Paquin, et al.. Do Deep Eutectic Solvents Form Uniform Mixtures Beyond Molecular Microheterogeneities?. Journal of Physical Chemistry B, 2020, 124 (41), pp.9126-9135. 10.1021/acs.jpcb.0c06317 . hal-02943072

\section{HAL Id: hal-02943072 \\ https://hal.science/hal-02943072}

Submitted on 18 Sep 2020

HAL is a multi-disciplinary open access archive for the deposit and dissemination of scientific research documents, whether they are published or not. The documents may come from teaching and research institutions in France or abroad, or from public or private research centers.
L'archive ouverte pluridisciplinaire HAL, est destinée au dépôt et à la diffusion de documents scientifiques de niveau recherche, publiés ou non, émanant des établissements d'enseignement et de recherche français ou étrangers, des laboratoires publics ou privés. 


\title{
Do Deep Eutectic Solvents Form Uniform Mixtures
}

\section{Beyond Molecular Microheterogeneities?}

\author{
Lucie Percevault $^{\mathrm{a}}$, Aicha Jani ${ }^{\mathrm{b}}$, Thibaut Sohier ${ }^{\mathrm{b}}$, Laurence Noirez ${ }^{\mathrm{c}}$, Ludovic Paquin ${ }^{\mathrm{a}}$, Fabienne \\ Gauffre $^{\mathrm{a}}$, Denis Morineau*b
}

${ }^{a}$ Institute of Chemical Sciences of Rennes, CNRS-University of Rennes 1, UMR 6251, F-35042 Rennes, France

${ }^{b}$ Institute of Physics of Rennes, CNRS-University of Rennes 1, UMR 6226, F-35042 Rennes, France
'Laboratoire Léon Brillouin (CEA-CNRS), CEA-Saclay, Université Paris-Saclay, F-91191 Gif- sur-Yvette, France

ABSTRACT We have performed small angle neutron scattering (SANS) in a momentum transfer range $\left(0.05<Q<0.5 \AA^{-1}\right)$ to study long range order and concentration fluctuations in deep eutectic solvents (DESs) and their aqueous solutions. Ethaline (choline chloride:ethylene glycol), glycerol:lactic acid, and menthol:decanoic acid mixtures were selected to illustrate respectively the case of ionic, nonionic and hydrophobic mixtures. Different carefully designed isotopic labelling was used to emphasize selectively the spatial correlations between the different solvent components. For ethaline DESs and their aqueous solutions, a weak low- $Q$ peak observed only for certain compositions and some partial structure factors revealed the mesoscopic segregation of ethylene glycol molecules that do not participate to the solvation of ionic units, either because they are in excess with respect the eutectic stoichiometry (1:4 neat ethaline) or substituted by water 
(4w-ethaline and higher aqueous dilutions). For the nonionic hydrophilic solutions, such a mesoscopic segregation was not observed. This indicates that the better balanced interactions between the three nonionic H-bonded components (water, lactic acid, and glycerol) favor homogeneous mixing. For the hydrophobic DESs, we observed an excess of coherent scattering intensity centered at $Q=0$, which could be reproduced by a model of non-interacting spherical domains. Local concentration fluctuations are not excluded either. However, unlike liquid mixtures with a tendency to demix, we have found no evidence of expansion of domains with different compositions to a large scale.

Corresponding Author: * E-mail: denis.morineau@univ-rennes1.fr

\section{TOC GRAPHIC}

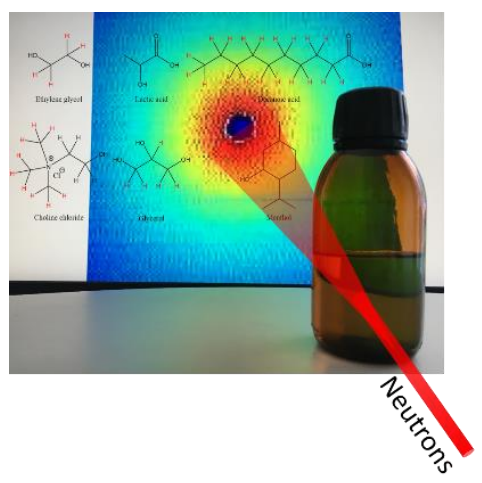




\section{Introduction}

Since their recent introduction as a promising alternative to classical solvents, the interest in deep eutectic solvents (DESs) has increased continuously., 2 They are considered as more affordable and usually less toxic variants of the room temperature ionic liquids. In the meantime, they retain most of the advantages of their ionic counterparts, including low volatility, and high solvating and extracting properties. The performances of DESs have been considered for practical applications in a growing number of industrial processes, including extraction, (bio)synthesis, catalysis, electrochemistry, and carbon dioxide capture..$^{3-5}$

According to their initial description, DESs are formed by the mixing of an H-bond donor (HBD) with an H-bond acceptor (HBA) or with a molecular ionic species (such as a quaternary ammonium). The existence of an eutectic point in the phase diagram of the as-formed binary mixture induces a large depression of its melting point. ${ }^{6,7}$ This forms a phase that remains in the liquid state below room temperature even though its constituents melt at a much higher temperature. It is also expected that the strong ionic and H-bonding interactions favor specific spatial correlations between the DES constituents. ${ }^{8,9}$ The resulting non-ideal mixing effects could explain the exceptional lowering of the melting point of certain DESs.

In the quest of solvents with carefully designed functional properties, a series of different types

of mixtures was prepared and studied, including nonionic, hydrophobic or natural systems. ${ }^{3-5}$ Accordingly, the attributes of DESs enounced in the initial definitions have been considered in a more loose way, as regards to non-ideal mixing and the relation to the eutectic composition. For practical reasons, aqueous solutions of DESs have been formulated and their physical properties, 
including excess properties, viscosity, acoustic, structural and optical properties have been studied thoroughly. ${ }^{9-21}$ These works have also raised the question of the resilience of the specific local arrangement of DES during dilution with water and its evolution towards an aqueous solution of its constituents..$^{9-11,19,22}$

The structure of DESs has attracted a lot of interest during the last four years. Hammond et al. have performed wide angle neutron scattering (WANS) experiments fitted to an Empirical Potential Structure Refinement (EPSR) model for reline (1:2 choline chloride:urea) ${ }^{23}$ This study showed that reline formed stoichiometric supramolecular ionic complexes, which are composed of H-bonded coordinating choline and urea strongly interacting with chloride anions. Complementing this pioneering work, WANS studies reported complexed ionic clusters for choline chloride based DESs with different HBD. ${ }^{22,24,25}$ The principal role of the HBD-chloride anion interactions in controlling the formation of supramolecular solvated units was generally pointed out. However, it was shown that changing the composition or the temperature impacts the stability and stoichiometry, as well as the role of choline cation as a secondary HBD participant. Fluorescence and infrared spectroscopy studies demonstrated that changing the hydrocarbon chain length of both HBA and HBD affects the spatial and dynamic heterogeneity of the ionic DESs. ${ }^{26-}$ ${ }^{28}$ This view is in line with conclusions from WANS on alkylammonium bromide:glycerol DESs ${ }^{29}$ and MD simulation of choline chloride derivatives:ethylene glycol DESs ${ }^{30}$ that have related the microheterogeneous structure of DESs to the segregation of the apolar and polar groups of the cationic molecules into separated domains. The formation and the percolation of these domains are favored by larger chains, which reveal the role of the amphiphilic character of the cationic moieties. Interestingly, these supramolecular assemblies reflect the non-ideal character of DESs. In fact, it was concluded from a systematic studies of reline, glyceline (choline chloride:glycerol), 
and ethaline (choline chloride:ethylene glycol) DESs by QM/MD simulation that the extension of the hydrogen bond network between the HBD and the ionic species was correlated with the enhanced depression of the melting point. ${ }^{31}$ The effects of non-ideal mixing in both the structure and some physicochemical properties (for instance, the lowering of the melting point) of DESs and DES dilutions, were stressed in recent studies of a ternary DES composed of $\mathrm{ChCl}$, urea and resorcinol diluted in either water or benzylalcohol. Using both MD simulations and neutron scattering with isotopic substitution together with empirical potential structure refinement as well as Brillouin and NMR spectroscopies, these studies described how, in the so-called solvent-inDES regime, solvent molecules participated in the H-bond complexes of the original DESs as an additional HBD. ${ }^{32,33}$

Another aspect of special interest is the observation of a low- $Q$ peak centered about the momentum transfer $Q=0.15-0.3 \AA^{-1}$ (also denoted prepeak) in the simulated neutron and X-ray scattering static structure factor of $\mathrm{Li}^{+} / \mathrm{ClO}_{4}{ }^{-}$:alkylamide DES. ${ }^{34,35}$ This prepeak is the fingerprint of intermediate range order, in line with similar observations commonly made for ionic liquids or alcohols. ${ }^{36,37}$ For reline and ethaline, there is no noticeable prepeak in the total structure factor. ${ }^{8,}$ ${ }^{38}$ However, according to these MD simulations, this observation was due to cancellation effects. ${ }^{8}$ In fact, prepeaks were observed in simulated partial structure factors, and they were attributed to the presence of unique intermediate range structural ordering. More specifically for ethaline, a prepeak predicted at about $Q=0.5 \AA^{-1}$ was related to ethylene glycol (EG) homo-molecular correlations (i.e. EG-EG correlations). ${ }^{8}$ Due to the lack of experimental scattering data for ethaline DES, this recent prediction has not been verified so far.

Compared to ion-based DESs, there is less literature on structural studies of DESs that do not comprise ionic salts or organic cations. We denote these systems as "nonionic DESs", 
notwithstanding the presence of carboxylic acid groups. Microheterogeneous structures produced by segregation of polar/non-polar molecular groups forming nanoscopic domains have been evidenced by IR spectroscopy for N-methylacetamide:lauric acid DES. ${ }^{39}$ There are also evidences that lauric acid molecules form micellar structures in DESs with a size corresponding to two lauric acids, which is further supported by the presence of a prepeak at $Q=0.25 \AA^{-1}$ in the X-ray scattering intensity. ${ }^{40}$

Given the amphiphilic nature of many DES ingredients, the structure of their aqueous solutions is a particularly exciting topic. Neutron scattering experiments and MD simulation point out the preferential solvation of chloride by water in choline chloride based DESs. ${ }^{10,16,41,42}$ However, the supramolecular ionic clusters formed by the association of the initial DES components seem resistant to moderate hydration levels. ${ }^{22,} 43$ Although aqueous solutions of reline were demonstrated not to be classically phase-separated,${ }^{10}$ it is noteworthy that microphase segregation and the formation of co-continuous structures were evidenced by NMR and Brillouin spectroscopy in various water-DES mixtures. ${ }^{18,19,44}$ The detailed nature of such microphase separated structure is still under discussion. On one hand, the formation of large water clusters (e.g. $1 \mathrm{~nm}$ ) was dismissed for malic acid:choline chloride:water (1:1:2), water rather forming a transient, wormlike aggregates that rarely exceed two molecules in width. ${ }^{22}$ On the other hand, recent MD simulation of ethaline water mixtures, revealed that the growth of long-range density fluctuations on increasing the hydration level was more specifically attributed to the segregation of the HBD molecules (i.e. ethylene glycol) in the pool of the aqueous mixture. ${ }^{9}$ This is supported by the existence of multimers composed of strongly H-bonded ethylene glycol molecules in aqueous solution of ethaline as demonstrated by infrared spectroscopy and DFT quantum calculations. ${ }^{45}$ According to the above-mentioned predictions from MD simulation, the mesoscopic structural 
ordering of ethylene glycol molecules during water addition should be evidenced by the raising of a low- $Q$ component $\left(0.1 \leq Q \leq 0.25 \AA^{-1}\right)$ for the EG-EG partial structure factor, but it could not be seen in the total $S(Q)$ due to cancellation effects. ${ }^{9}$ Experimentally, conventional X-rays and neutron diffraction methods provide a weighted sum of all partial structure factors, which is likely also affected by the cancellation effects. Small angle neutron scattering experiment with isotopic labelling offers a unique possibility to measure the partial structure factors and detect this low- $Q$ component.

The aim of the present work is to study the large scale structure of DESs from the analysis of the static structure factor in the range of low momentum transfer $\left(0.05 \leq Q \leq 0.5 \AA^{-1}\right)$, which has been barely investigated experimentally so far. This study benefited from the high resolution of small angle neutron scattering. Inspired by recent predictions made from molecular simulations for ethaline DES and ethaline DES aqueous solutions, we highlighted specifically intermolecular correlations by isotopic labelling in order to reveal partial structure factors ${ }^{8,9}$ Neutron scattering with isotopic substitution offers a unique method to achieve this molecular labelling as illustrated by studies of the mesoscopic structure of classical liquid mixtures ${ }^{46}$ Different compositions and different types of solvents were studied, spanning from ionic to nonionic, hydrophobic to hydrophilic, as well as aqueous solutions in order to bring a broad view of possible long range order in DES and related H-bonded liquid mixtures for a series of prototypical cases.

Ethaline mixtures were selected as typical systems representing the class of ionic DESs. Mixtures of lactic acid with glycerol fall in the category of hydrophilic nonionic solutions. Both molecules have been used in the literature as HBD constituents of DESs formed by mixing with choline chloride, ${ }^{47}$ and their mixtures have been applied for the treatment of biomass. ${ }^{48}$ In the present work, we have studied lactic acid:glycerol mixtures by comparison to ethaline DESs in 
order to determine the impact of switching-off the electrostatic interactions. Indeed, apart from a small difference concerning the HBD (glycerol instead of ethylene glycol), the main difference between these two systems is the substitution of the HBA ionic choline chloride by the non-ionic (or partially ionic) H-bonded carboxylic acid. The effects of adding water to both of these hydrophilic solvents were also investigated. Finally, different menthol:decanoic acid mixtures were studied as members of the class of hydrophobic DES. ${ }^{49}, 50$

\section{Methods}

\subsection{Samples.}

Fully hydrogenated choline chloride (>99\%) and ethylene glycol (anhydrous, 99.8\%) and DLMenthol ( $\geq 95 \%)$ were purchased from Sigma-Aldrich and lactic acid (extra pure, SLR) from Fisher scientific. Partially deuterated choline chloride (trimethyl $\mathrm{D}_{9}, 98 \% \mathrm{D}$ ), ethylene glycol (1.1.2.2 $\left.\mathrm{D}_{4}, 99 \% \mathrm{D}\right)$, decanoic acid $\left(\mathrm{D}_{19}, 98 \%\right)$ and glycerol $\left(1.1 .2 .3 .3 \mathrm{D}_{5}, 99 \% \mathrm{D}\right)$ were purchased from Eurisotop. The structure of the molecules are illustrated in Figure 1, and the isotopically labelled sites are highlighted. 


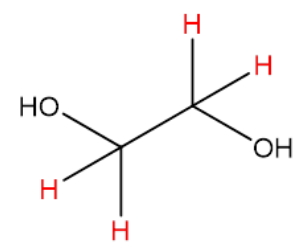

Ethylene glycol

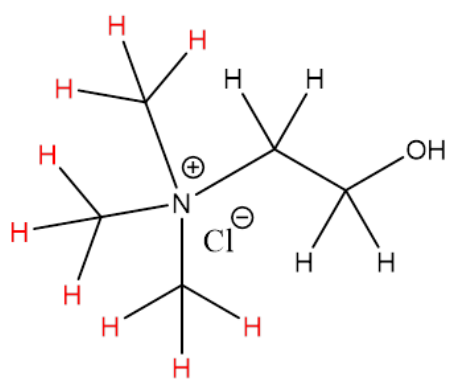

Choline chloride

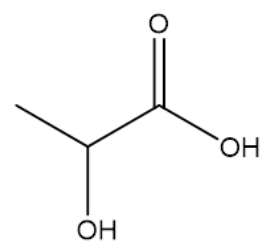

Lactic acid

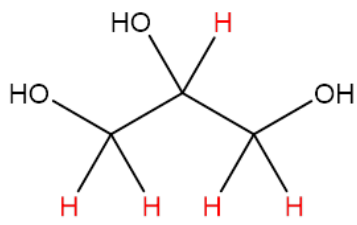

Glycerol

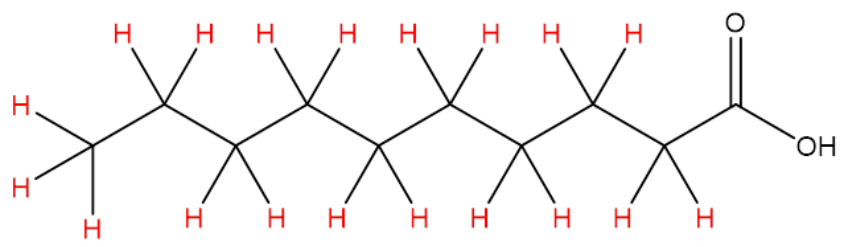

Decanoic acid

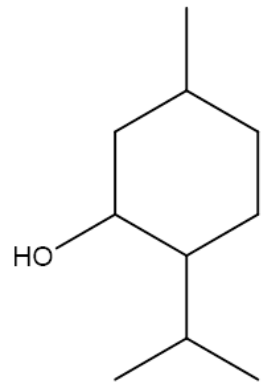

Menthol

Figure 1. Molecular structure of the chemicals studied. The hydrogen sites that were isotopically labelled are colored in red.

Mixtures were prepared by weighting and adding their constituents. The constituents were mixed by mechanical agitation at about $60^{\circ} \mathrm{C}$ for a duration between 30 min to 4 hours until a clear homogeneous liquid phase was obtained and served as stock solutions. For hydrophilic solvents, series of aqueous solutions were prepared from the mother solutions by pipetting and addition of deionized water.

The chemical composition of the different systems is given in the Table 1. It should be noted that different isotopic variants were also prepared for ethaline and ethaline DESs aqueous solution, as described later. Note that the labile hydroxyl and acid groups were not deuterated in order to avoid isotopic exchange with water.

Table 1. Composition of the DESs and aqueous solutions studied 


\begin{tabular}{|l|l|l|l|l|}
\hline DES type & Constituents & $\begin{array}{l}\text { Chemical } \\
\text { composition }\end{array}$ & $\begin{array}{l}\text { Water mass } \\
\text { fraction (\% wt) }\end{array}$ & $\begin{array}{l}\text { Isotopic } \\
\text { composition }\end{array}$ \\
\hline Neat ionic DES & $\begin{array}{l}\text { Ethylene glycol:choline } \\
\text { chloride (Ethaline) }\end{array}$ & $(4: 1),(3: 1),(2: 3: 1)$ & - & $\begin{array}{l}\left(\mathrm{H}_{6}: \mathrm{D}_{9} \mathrm{H}_{5}\right), \\
\left(\mathrm{D}_{4} \mathrm{H}_{2}: \mathrm{H}_{14}\right)\end{array}$ \\
\hline $\begin{array}{l}\text { Ionic DES } \\
\text { solution }\end{array}$ & $\begin{array}{l}\text { Ethylene glycol:choline } \\
\text { chloride:water }\end{array}$ & $\begin{array}{l}(2: 1: w) \\
\text { with } w=0,0.8,1.7, \\
2.7,4,6.5,10\end{array}$ & $\begin{array}{l}0,5,10,15,20, \\
30,40\end{array}$ & $\begin{array}{l}\left(\mathrm{D}_{4} \mathrm{H}_{2}: \mathrm{D}_{9} \mathrm{H}_{5}: \mathrm{H}_{2} \mathrm{O}\right), \\
\left(\mathrm{H}_{6}: \mathrm{D}_{9} \mathrm{H}_{5}: \mathrm{H}_{2} \mathrm{O}\right), \\
\left(\mathrm{D}_{4} \mathrm{H}_{2}: \mathrm{H}_{14}: \mathrm{H}_{2} \mathrm{O}\right)\end{array}$ \\
\hline $\begin{array}{l}\text { Nonionic H- } \\
\text { bonded solution }\end{array}$ & Lactic acid:glycerol:water & $\begin{array}{l}(1: 2: w) \\
\text { with } w=0,1,2,3,30\end{array}$ & $0,6,10,15,66$ & $\left(\mathrm{H}_{6}: \mathrm{D}_{5} \mathrm{H}_{3}: \mathrm{H}_{2} \mathrm{O}\right)$, \\
\hline $\begin{array}{l}\text { Hydrophobic } \\
\text { DES }\end{array}$ & Menthol:decanoic acid & $\begin{array}{l}(2: 3),(1: 1),(3: 2), \\
(2: 1),(3: 1),(4: 1)\end{array}$ & - & $\left(\mathrm{H}_{20}: \mathrm{D}_{19} \mathrm{H}\right)$, \\
\hline
\end{tabular}

\subsection{SANS Experiments.}

Small-angle neutron scattering experiments were performed using the PAXY diffractometer (LLB, Saclay). The sample detector distance chosen was $1 \mathrm{~m}$ and the neutron wavelength used was $5 \AA$ allowing the measurement of the diffracted intensity in a momentum transfer range $(0.05$ $<Q<0.5 \AA^{-1}$ ). The measurements were conducted at room temperature with a thermal bath regulator set to $24.5^{\circ} \mathrm{C}$. Complementary measurements were also performed at $15^{\circ} \mathrm{C}$ and $39^{\circ} \mathrm{C}$ for comparison. The solutions were prepared in advance so the mixtures are thermodynamically at equilibrium. The solutions were filled in $1 \mathrm{~mm}$ thick quartz Hellma cells. The raw intensities were corrected from the empty cell contribution by subtraction of the filled and empty cell spectra, divided by the corresponding transmission. The correction of the systematic variation of the detector efficiency and normalization of $I(Q)$ to absolute unit was performed with respect to the measured intensity of a $1 \mathrm{~mm}$ thick hydrogenated water of known value of its incoherent cross section $\left(\sum_{\text {incoh }} / 4 \pi=0.445 \mathrm{~cm}^{-1}\right)$ using the data reduction software PASiNET from Laboratoire Léon Brillouin.

Particular attention has been paid to the use of contrast effects in order to reveal specific correlations stemming from partial structure factors. A large variation of the coherent neutron 
scattering of the different DESs components was achieved using D/H isotopic labelling, as indicated in Table 2 for the ethaline aqueous solutions, and discussed thereafter.

Table 2. Neutron coherent scattering length density of the components of ethaline DES and ethaline aqueous solutions for three different isotopic compositions. The cell background colors indicate the highest scattering contrast between the different compounds.

\begin{tabular}{|c|c|c|c|}
\hline Neutron scattering length density $\rho_{S L D}\left(10^{9} \mathrm{~cm}^{-2}\right)$ & $\begin{array}{l}\text { Ethylene } \\
\text { glycol (EG) }\end{array}$ & $\begin{array}{l}\text { Choline } \\
\text { chloride (ChCl) }\end{array}$ & Water \\
\hline ETHA-W(DDH) : $\mathrm{EG}\left(\mathrm{D}_{4} \mathrm{H}_{2}\right) / \mathrm{ChCl}\left(\mathrm{D}_{9} \mathrm{H}_{5}\right) /$ Water $\left(\mathrm{H}_{2} \mathrm{O}\right)$ & 47 & 47 & -5 \\
\hline ETHA-W(HDH) : EG( $\left.\mathrm{H}_{6}\right) / \mathrm{ChCl}\left(\mathrm{D}_{9} \mathrm{H}_{5}\right) /$ Water $\left(\mathrm{H}_{2} \mathrm{O}\right)$ & 2 & 47 & -5 \\
\hline ETHA-W(DHH) : EG( $\left(\mathrm{D}_{4} \mathrm{H}_{2}\right) / \mathrm{ChCl}\left(\mathrm{H}_{14}\right) /$ Water $\left(\mathrm{H}_{2} 0\right)$ & 47 & 2 & -5 \\
\hline ETHA(HD) : $\mathrm{EG}\left(\mathrm{H}_{6}\right) / \mathrm{ChCl}\left(\mathrm{D}_{9} \mathrm{H}_{5}\right)$ & 2 & 47 & \\
\hline ETHA(DH) : EG( $\left(\mathrm{D}_{4} \mathrm{H}_{2}\right) / \mathrm{ChCl}\left(\mathrm{H}_{14}\right)$ & 47 & 2 & \\
\hline
\end{tabular}




\section{Results and discussion}

\subsection{Neat ionic DES: ethaline (ethylene glycol:choline chloride)}

Ethaline DES (ethylene glycol:choline chloride) was studied in a molar ratio of 2.3:1, 3:1 and $4: 1$, which is in the region of maximum freezing depression. ${ }^{51,52}$ In order to highlight the coherent scattering of one of the two components, two isotopic variants of each DESs were prepared mixing a deuterated component, which maximizes its coherent scattering with respect to the hydrogenated one (named ETHA(HD) and ETHA(DH)). The values of the coherent scattering length density of each molecule are summarized in Table 2. They were determined according to the classical definition by $\rho_{S L D}=\frac{\sum b_{i}}{v}$, where $b_{i}$ is the coherent scattering length of atom $i$, the sum being performed over all the atoms constituting one molecule, and $v$ is the molecular volume. The two deuterated molecules have comparable scattering length density $\left(47.10^{9} \mathrm{~cm}^{-2}\right)$, while their fully hydrogenated forms $\left(2.10^{9} \mathrm{~cm}^{-2}\right)$ rather compare with water $\left(-5.10^{9} \mathrm{~cm}^{-2}\right)$. It is thus expected that the coherent scattering for ETHA(HD) and ETHA(DH) mostly reflect the partial structure factors arising respectively from choline chloride and ethylene glycol. 
Choline Chloride $\left(\mathrm{D}_{9} \mathrm{H}_{5}\right)$ / Ethylene Glycol $\left(\mathrm{H}_{6}\right)$

Choline Chloride $\left(\mathrm{H}_{14}\right)$ / Ethylene Glycol $\left(\mathrm{D}_{4} \mathrm{H}_{2}\right)$
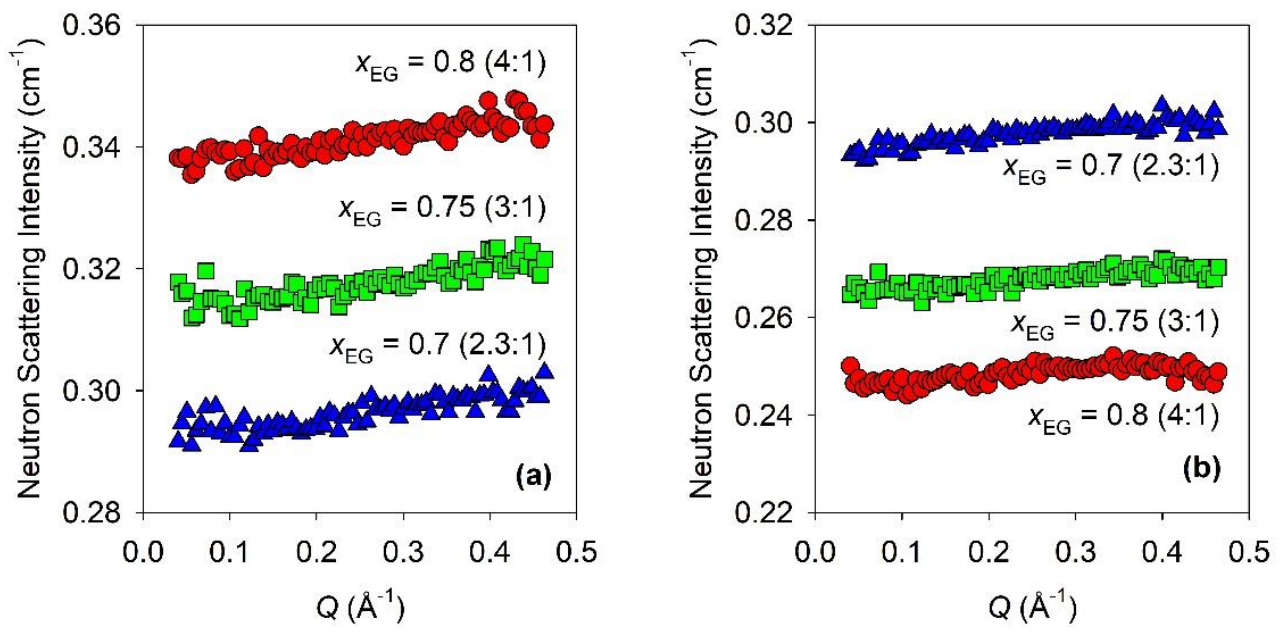

Figure 2. Neutron scattering intensity of ethaline DESs measured at $24.5{ }^{\circ} \mathrm{C}$ for values of for three molar compositions corresponding to ethylene glycol:choline chloride in mol ratio $2.3: 1,3: 1$, and 4:1. The different panels correspond to different isotopic labeling of the two components of ethaline: (a) deuterated choline chloride ETHA(HD), (b) deuterated ethylene glycol ETHA(DH).

The main effect of changing the $\mathrm{EG}: \mathrm{ChCl}$ mol ratio (cf. Figure 2) consists in a net increase of the total scattered intensity with the fraction of hydrogenated molecules. This is obviously attributed to the incoherent scattering, which mostly arises from hydrogen contribution. The coherent scattering, which is $Q$-dependent, is weak in the studied $Q$-range. For ETHA(HD), illustrated in Figure 2a, we observed a monotonous decrease of the intensity from the medium $(0.5$ $\left.\AA^{-1}\right)$ to small $\left(0.05 \AA^{-1}\right) Q$ values. This contribution is attributed to the low- $Q$ side of the main diffraction peak arising from short range intermolecular order. According to recent computations of the structure factor, the maximum of the main diffraction peak is located around $Q=1.5 \AA^{-1}$, and thus outside the $Q$-range accessible to our SANS measurements. ${ }^{8}$ In the absence of mesoscale 
heterogeneity, this intensity classically decreases to small values determined by the liquid compressibility in the limit of vanishing $Q$ 's. For ETHA(DH) however, we observed a deviation from this monotonous variation with the occurrence of a weak additional broad peak around $Q=$ $0.35 \AA^{-1}$ for ethylene glycol:choline chloride (4:1) as illustrated in Figure $2 \mathrm{~b}$. Such a prepeak was recently witnessed in the EG-EG partial structure factor of ethaline, and attributed to long-range correlations dominated by ethylene glycol molecules. ${ }^{8}$ Our observation made for the specific isotopic composition that enhanced EG-EG correlations is consistent with this prediction. So far, MD simulations are restricted to one composition (2:1). The present SANS results suggest that this prepeak is mostly visible for larger amount of ethylene glycol. We infer that having ethylene glycol molecules in excess with respect to the stoichiometric composition of the DES favors their segregation and the long-range extension of hydrogen bonding interactions among them. Finally, we can also conclude that the temperature effect is small on the range from $15^{\circ} \mathrm{C}$ to $39^{\circ} \mathrm{C}$, as demonstrated by the weak variation of the neutron scattering intensity shown in Figure S1.

\subsection{Aqueous solutions of ionic DES (ethylene glycol:choline chloride)}

Aqueous solutions of ethaline are made of a ternary mixture (ethylene glycol:choline chloride:water). In order to detect structural microheterogeneities; i.e. spatial correlations of the local concentration, it is therefore useful to label specifically each of the three compounds. Three different systems were considered composed of normal water $\left(\mathrm{H}_{2} \mathrm{O}\right)$ and ethaline in which one or both components were partially deuterated. Therefore, the low- $Q$ scattered intensity from ETHA$\mathrm{W}(\mathrm{DDH})$, ETHA-W(HDH) and ETHA-W(DHH) should reflect the local inhomogeneity of 
concentration in ethaline as a whole, choline chloride, and ethylene glycol, respectively. The contrast of coherent scattering between the different compounds is indicated in Table 2 .

The effect of adding water was studied for one DES composition $\left(x_{\mathrm{EG}}=0.67\right)$, which is ethylene glycol:choline chloride in a constant $2: 1 \mathrm{~mol}$ ratio that is in the vicinity of the eutectic point. The corresponding neutron scattering intensity is illustrated in Figure 3 for different values of the water mass fraction $W$ (from 0 to $40 \%$ ). Each of the three panels corresponding to a specific isotopic labelling. Adding water to the given DES consists in a net increase of the incoherent scattering. It was verified that the experimentally measured baseline of the scattered intensity was in quantitative agreement with the calculated incoherent scattering cross section of the different mixtures.
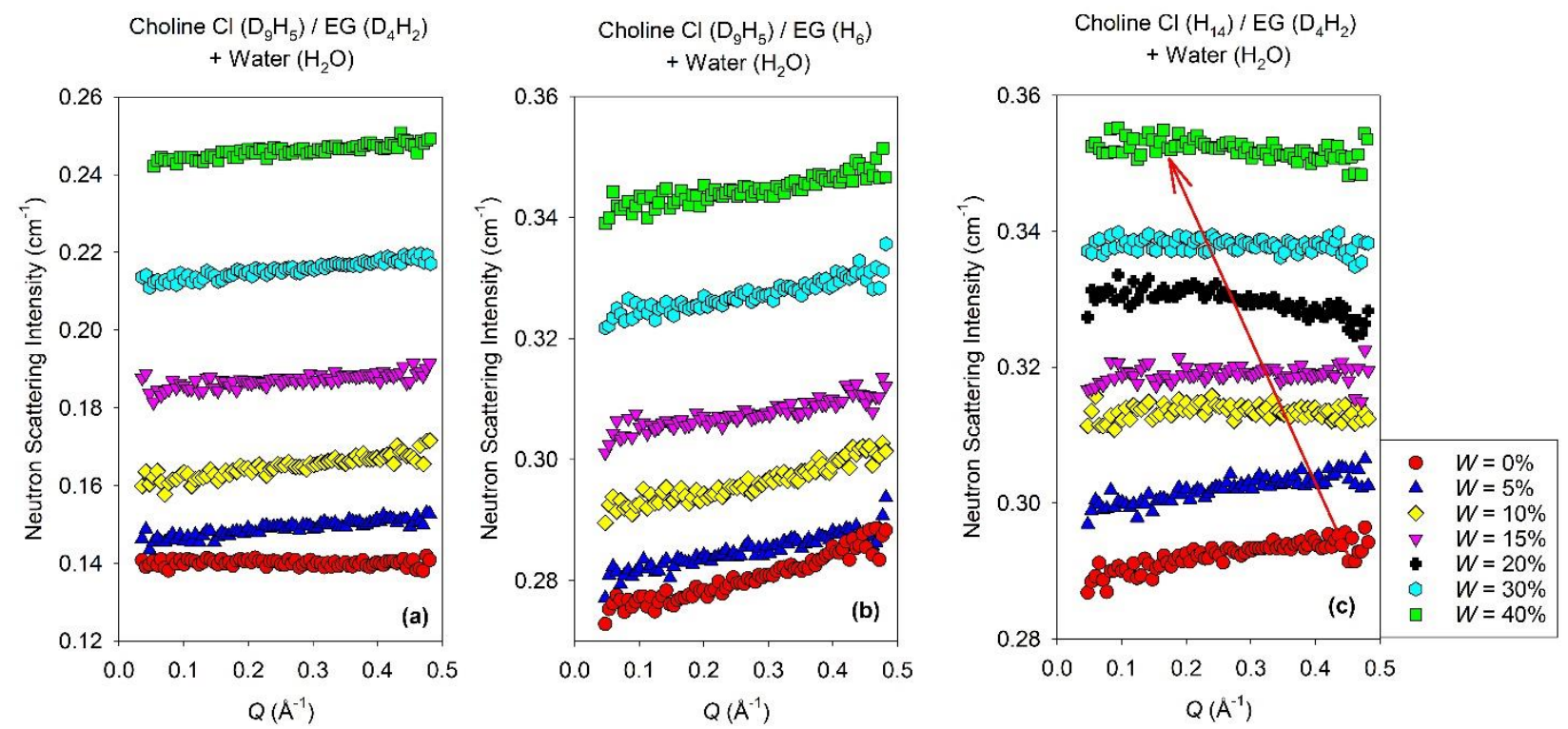

Figure 3. Neutron scattering intensity of ethaline DES aqueous solutions with ethylene glycol:choline chloride in mol ratio 2:1, and for values of the water mass fraction $W$ ranging from 
0 to $40 \%$ from bottom to top. The different panels correspond to different isotopic labeling of the two components of ethaline: (a) deuterated choline chloride and ethylene glycol ETHA-W(DDH), (b) deuterated choline chloride ETHA-W(HDH), (c) deuterated ethylene glycol ETHA-W(DHH). The shift to low $Q$-values of the maximum intensity of the broad peak is indicated by the red arrow in panel c.

For ETHA-W(DDH), and ETHA-W(HDH) (Figures 3a and 3b), we observed a weakly decreasing intensity when $Q$ decreased from medium $\left(0.5 \AA^{-1}\right)$ to small values $\left(0.05 \AA^{-1}\right)$, which is similar to the case of ETHA(HD) discussed in the previous part. Likewise, this profile is attributed to the low- $Q$ side of the main diffraction peak. Only for ETHA-W(DHH) (Figure 3c), we observed an additional broad peak that shifted from medium to small $Q$ values when the fraction of water increased. The peak is indicated by a red arrow in Figure 3c. In order to highlight the effect of the isotopic labeling, we compared on the same graph the scattered intensity of ETHA-W(HDH) and ETHA-W(DHH) for the two limits of water fraction studied; i.e. $W=0 \%$ in Figure $4 \mathrm{a}$ and $W=$ $40 \%$ in Figure 4b. The importance of isotopic contrast to reveal the low- $Q$ peak is highlighted in Figure $4 \mathrm{~b}$ from a comparison of ETHA-W(HDH) and ETHA-W(DHH) for $W=40 \%$, where the prepeak revealed for ETHA-W(DHH) is underlined by a red arrow. The scattered intensity for all the water fractions studied is illustrated in the Supporting Information. 

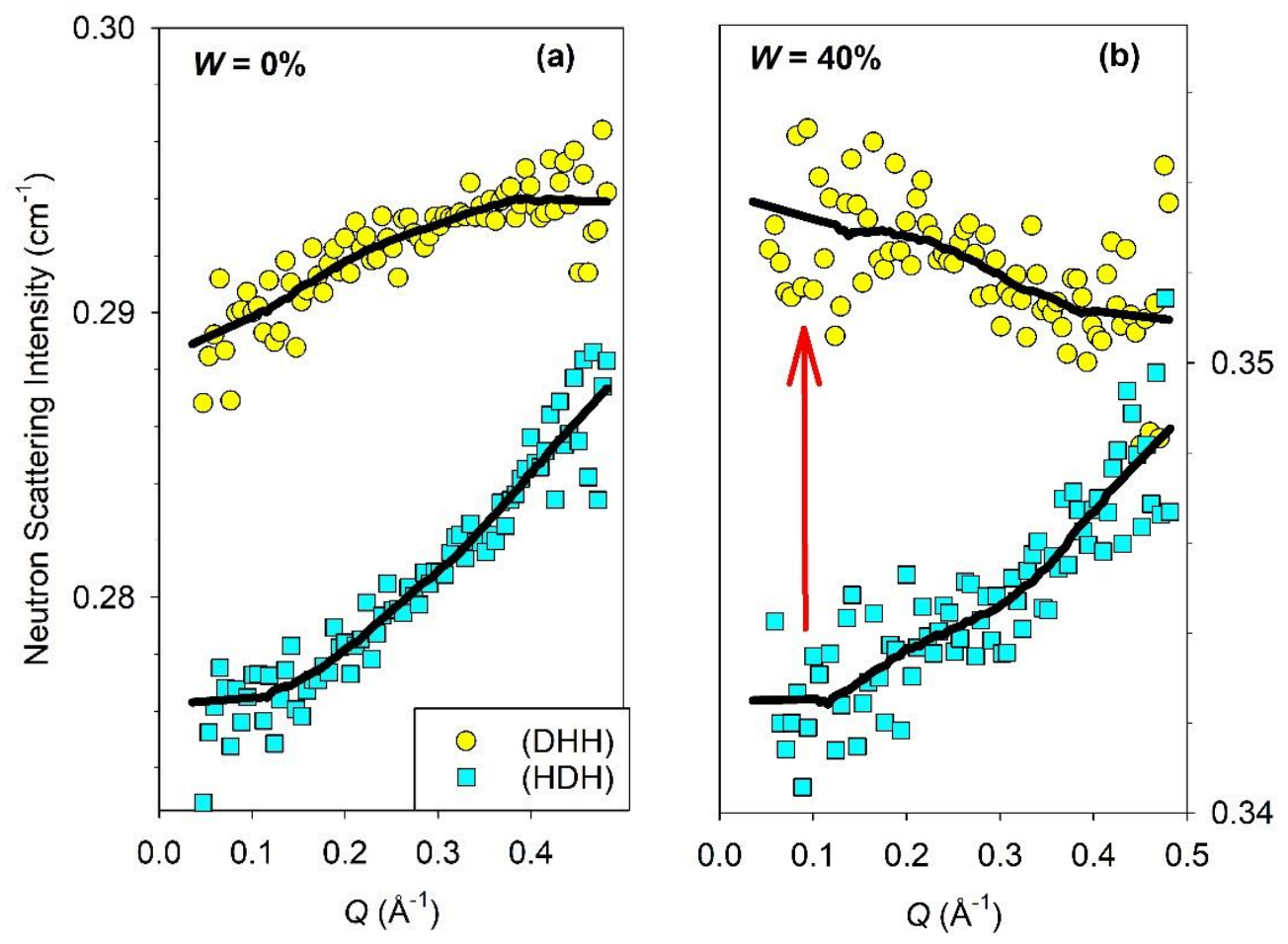

Figure 4. Use of a specific labelling to reveal the intermediate range structuration of ethylene glycol in ethaline aqueous solutions. Deuterated choline chloride ETHA-W(HDH) (squares) and deuterated ethylene glycol ETHA-W(DHH) (circles). The solid line is a smooth of the data. The value of the water mass fraction is (a) $W=0 \%$ and (b) $W=40 \%$. The growth of a low- $Q$ peak is indicated by a red arrow.

The intensity remained small, which means that the heterogeneous character of the ethaline solution is not pronounced at the nanometer scale. Interestingly, our observation is in agreement with the simulated partial structure factor of ethaline-water solutions. ${ }^{9}$ It was predicted that a prepeak shows up specifically in the EG-EG partial structure factor in the $Q$ range $0.1-0.25 \AA^{-1}$. In line with the present SANS data, it was shown that the intensity of this prepeak increases with increasing the water amount and shifts to small $Q$. In that study, the largest intensity was obtained 
for the more diluted solution (i.e. 5-w ethaline), corresponding to a prepeak position centered about $0.13 \AA^{-1}$. This is consistent with the result that we obtained experimentally for the closest studied composition $W=20 \%$ (i.e. $4-w$ ethaline).

We infer that the addition of water in ethaline (similarly to the presence of superstoichiometrical EG molecules in the neat DES) favors the preferential association between ethylene glycol molecules. This could be the consequence of the preferential solvation of ionic species by water molecules, which compete with ethylene glycols that present a weaker H-bond donor character.

\subsection{Aqueous solutions of hydrophilic nonionic H-bonded mixtures (lactic acid:glycerol)}

The mixture of lactic acid with glycerol falls in the category of hydrophilic nonionic H-bonded solvents. It can be viewed as a variant of ethaline, with a substitution of the ionic species by a second H-bonded molecule. Hence, we switched-off the interaction between HBD and ionic species, which is an important component of the ethaline DES properties. We used a mixture of deuterated glycerol with hydrogenated lactic acid and water (i.e. GLY-LA-W(DHH)). This choice was made to emphasize the glycerol-glycerol correlations. In fact, this isotopic composition is similar to the case of ETHA(DH) and ETHA-W(DHH), for which prepeaks were observed. 


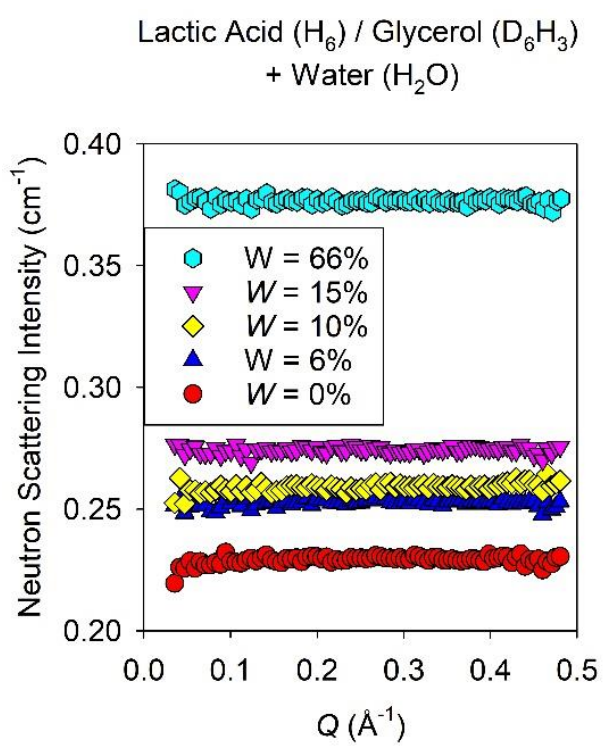

Figure 5. Neutron scattering intensity of lactic acid:deuterated glycerol aqueous solutions for values of the water mass fraction $W$ ranging from 0 to $66 \%$ from bottom to top.

Nonetheless, no prepeak could be detected in the small angle neutron scattered intensity illustrated in Figure 5. The entire intensity was dominated by the flat incoherent scattering (cf. also Figure 6), with no measurable coherent contribution. Unlike ethaline, this demonstrates the fully homogeneous character of lactic acid:glycerol mixture and its aqueous solutions $(W=0-66 \%)$ at the mesoscale. For ethaline, it was argued that the formation of strongly H-bonded ethylene glycol segregates was supplemented by the strongest affinity of water molecules with the ions. ${ }^{9}$ From that viewpoint, lactic acid and glycerol are much comparable molecules in terms of polarity, H-bonding tendency and weak amphilicity. They are both composed of a short alkyl part with three carbons and contain three H-bonding functional groups. Accordingly, we argue that the water affinity with one or the other components is more balanced. The propensity of lactic acid and glycerol to form either homomolecular or heteromolecular H-bonds is probably similar as well. This is confirmed by the SANS data that demonstrate the homogeneous mixing of the aqueous solutions down to the mesoscale. 


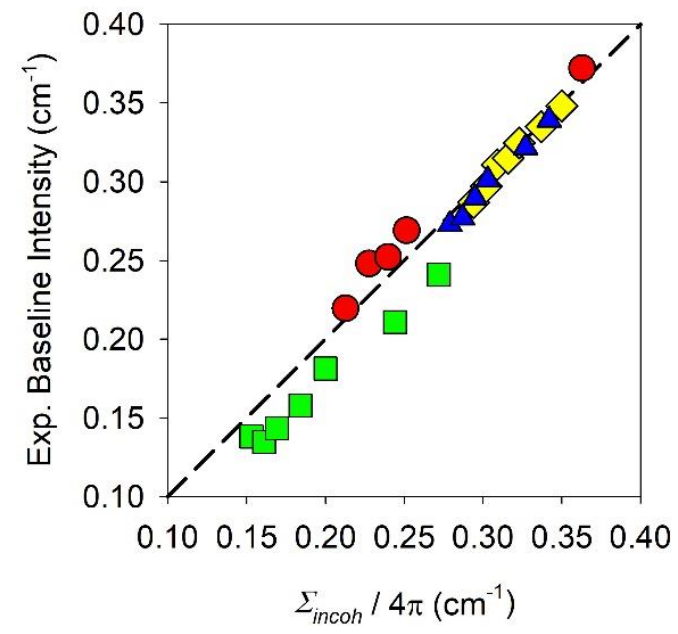

Figure 6. Comparison of the theoretical incoherent scattering cross section with the experimental neutron scattering intensity of different types of aqueous solutions and values of the water mass fraction. Ethaline with deuterated choline chloride and ethylene glycol (green square), ethaline with deuterated choline chloride (blue triangle), ethaline with deuterated ethylene glycol (yellow diamond), and lactic acid:deuterated glycerol (red circle) aqueous solutions. 


\subsection{Hydrophobic DES (menthol:decanoic acid)}

Finally, we discuss the DES made by mixing menthol and decanoic acid. This system falls in the category of hydrophobic DESs. ${ }^{49}, 50$ For this reason, instead of the water composition the relative amount of menthol and decanoic acid was varied. The menthol molar fraction $x$ ranged from 0.4 to 0.8 , which corresponds to stoichiometric compositions from $4: 1$ to $2: 3$. A unique isotopic composition was used, with a deuterated form of decanoic acid $\left(\mathrm{D}_{19} \mathrm{H}\right)\left(\rho_{S L D}=63.10^{9} \mathrm{~cm}^{-}\right.$ ${ }^{2}$ ) and hydrogenated glycerol $\left(\rho_{S L D}=6.10^{9} \mathrm{~cm}^{-2}\right)$ in order to maximize the contrast between the two compounds. The SANS experiments revealed a significant increase of the scattered intensity towards the limit of low $Q$ as illustrated in Figure 7. This peak was relatively broad and covered the entire studied $Q$-range. Its maximum position was located below the smallest accessible momentum, and seemingly centered at $Q=0$. Similar observations were reported in the literature for binary liquids, including alcohol:alkane mixtures and aqueous solutions of classical solvents as well as ionic liquids. ${ }^{36,46,53,54}$ They were attributed to concentration fluctuations that shows up at $Q=0$ according to the theory of Kirkwood-Buff integrals. In other words, it suggests that the distribution of molecular species in the system is not fully homogeneous. Following the analysis made for binary liquids, we first fitted the scattered intensity by eq. 1, which is composed by a Lorentzian centered at $Q=0$ with a fitted correlation length $\xi$ according to the Ornstein-Zernike theory and an incoherent scattering baseline, which values was determined from the liquid composition.

$$
I(Q)=\frac{I_{0}}{1+Q^{2} \xi^{2}}+\frac{\Sigma_{\text {incoh }}}{4 \pi}
$$


Menthol $\left(\mathrm{H}_{20}\right)$ - Decanoic acid $\left(\mathrm{D}_{19} \mathrm{H}\right)$

Menthol $\left(\mathrm{H}_{20}\right)$ - Decanoic acid $\left(\mathrm{D}_{19} \mathrm{H}\right)$
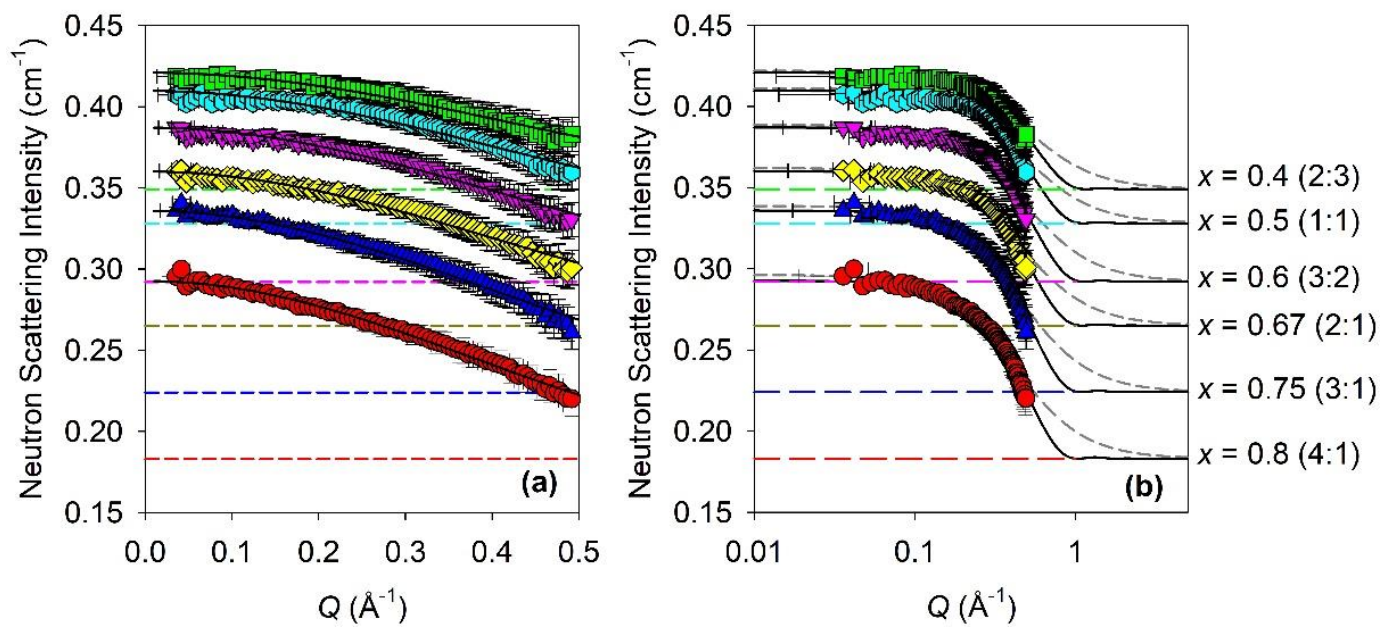

Figure 7. Neutron scattering intensity of menthol $\left(\mathrm{H}_{20}\right)$ :decanoic acid $\left(\mathrm{D}_{19}\right)$ DES mixtures for values of the menthol molar fraction $x$ ranging from 0.4 to 0.8 from top to bottom. (a) Linear scale, (b) semi-log scale. The incoherent scattering cross section (long dashed line), the fits with the form factor of a spherical particle (solid line) and the Ornstein-Zernike model (short dashed line).

The scattered intensity at zero- $Q$, which is directly related to the Kirkwood-Buff integrals, exhibited a weak dependence on the composition, with a maximum that is perceived around the equimolar composition despite the limited number of studied compositions. This variation is emphasized in Figure 8 by a quadratic term $x(1-x)$, which suggests a symmetric behavior of the mixture with respect the menthol and decanoic acid constituents.

Although generally satisfying, this model failed to accurately reproduce the decay of the experimental intensity at medium $Q\left(>0.4 \AA^{-1}\right)$ as illustrated in short dashed lines in Figure $7 \mathrm{~b}$. For comparison, we opted for an alternative description, which applies for liquid comprising domains of well-defined geometry such as micellar aggregates rather than ill-defined fluctuating aggregates. ${ }^{36,55}$ In the latter case, the scattered intensity writes as 


$$
I(Q)=n_{d} V_{d}^{2}\left(\Delta \rho_{S L D}\right)^{2} P(Q) S(Q)+\frac{\Sigma_{\text {incoh }}}{4 \pi}
$$

where $n_{d}$ and $V_{d}$ are the number density of domains and the volume of each of domains, $\Delta \rho_{S L D}$ is the difference of scattering length density between the domains and the surrounding phase. ${ }^{56}$ $P(Q)$ and $S(Q)$ are the form factor and structure factor, which quantify the shape of each domain and their spatial correlations, respectively. Satisfactory fits shown as solid lines in Figure $7 \mathrm{~b}$ were obtained by assuming that the domain shape is spherical with a radius $R_{d}$ so that $P(Q)$ is given by eq. 3. We further assumed that the interdomain interaction was negligible in this $Q$-range (i.e. $S(Q)$ $=1$, a point that was verified a posteriori as discussed later.

$$
P(Q)=9\left[\frac{\sin Q R_{d}-Q R_{d} \cos Q R_{d}}{\left(Q R_{d}\right)^{3}}\right]^{2}
$$

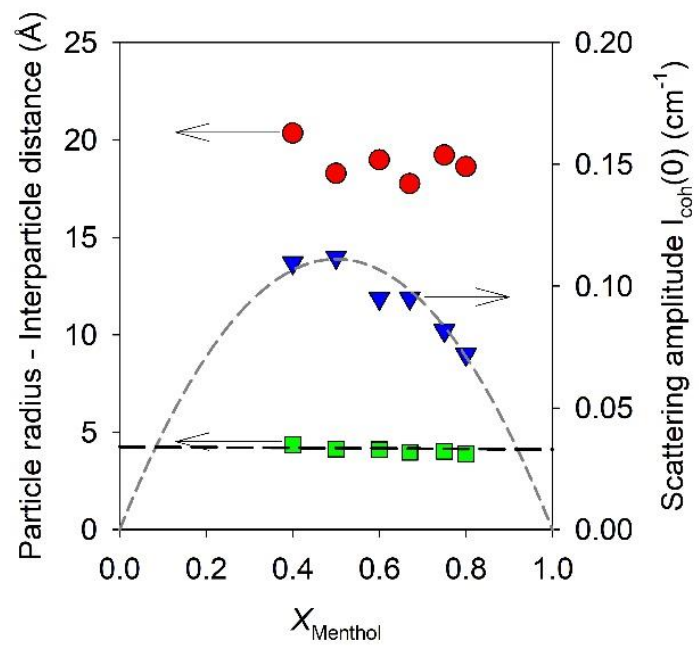

Figure 8. Parameters derived from the fitting of the neutron scattering intensity of menthol $\left(\mathrm{H}_{20}\right)$ :decanoic acid $\left(\mathrm{D}_{19}\right)$ DES mixtures as a function of the menthol molar fraction $x$. The domain radius (green square, left axis), the interdomain distance (red circle, left axis), and the coherent 
scattering amplitude (blue triangle, right axis). The averaged molecule radius computed from the average molecular volume (long dashed line) and a symmetric quadratic guideline $x(1-x)$ scaled to the coherent scattering (short dashed line).

The obtained parameters are illustrated in Figure 8. The domains radius is varying from about 4.4 to $3.9 \AA$. These values compare with the average radius of the molecules $r_{m}$, which was evaluated from the molecular volume $\left(v_{m}=\frac{4}{3} \pi r_{m}{ }^{3}\right)$ neglecting corrections due to non-additivity of the partial volume (cf. long dashed line in Figure 8). The fact that these domains do not present strong interactions (justifying the assumption that $S(Q)=1$ on the studied $Q$-range) was firstly supported by the absence of correlation peak at finite $Q$. This was confirmed by the average distance between domains, which could be evaluated from their number density $n_{d}$ that appears in eq. 3 as a scaling factor. Indeed, the obtained values are typically 4 times larger than $R_{d}$ as illustrated in Figure 8.

This demonstrates that this DES clearly exhibits structural heterogeneity, however the segregation of the two components is spatially limited. This differs from binary liquids with strong demixing tendency, such as aqueous solutions of ionic liquids or aqueous solutions of large alcohols and pyridine derivatives for which the measured correlation lengths usually exceed 10 $\AA .{ }^{54,55,57}$ On the other hand, it compares reasonably with the values obtained for ionic liquids. ${ }^{36}$, 58

Two alternative descriptions have been applied, either in terms of diluted well-shaped spherical aggregates such as micelles or in terms of shapeless concentration fluctuations, which are precursors of an underlying phase separation. However, due to the absence of interaction peaks and despite the slightly better fits obtained with the former model, we consider that the two 
descriptions can be acceptable. From this viewpoint, the mesoscale structure of DESs also deserves a comparison with the ionic liquids. Depending on the systems, the description of the low- $Q$ scattering intensity in terms of monodisperse hard-sphere interacting pseudospherical aggregates or structureless concentration fluctuations was preferred. ${ }^{36,58}$ The amphiphilic nature of the menthol and decanoic acid molecules comprising polar head and long aliphatic tail brings further support to the possible formation of micellar clusters. Variable temperature measurements could assess the presence of a miscibility gap and help resolve the physical origin of the observed mesoscopic structure in menthol:decanoic acid DES. 


\section{Conclusions}

Despite the rapidly increasing number of studies on the short and intermediate range order of DESs, small angle scattering techniques have been scarcely used to investigate their structure at longer distances. Important enough, recent molecular simulation studies have predicted the occurrence of low- $Q$ correlation peaks in ethaline ${ }^{8}$ and its aqueous solutions, ${ }^{9}$ which called for a further experimental examination with SANS methods.

We selected three types of prototypical solutions: a classical DES formed by the association of an H-bond donor and an ionic species, a hydrophilic nonionic mixture of H-bonded DES components and a hydrophobic DES. Moreover, we studied the effect of adding different amount of water in the two hydrophilic solutions. SANS experiments with isotopic labelling (H/D exchange) were carried out in order to vary the coherent scattering contrast between the different compounds and reveal mesoscopic static correlations in the partial structure factors for $Q$-values (0.05-0.5 $\left.\AA^{-1}\right)$ located before the main diffraction peak.

For ethaline DES and its aqueous solutions, a low- $Q$ coherent scattering was observed only when the EG-EG correlations were enhanced by specific deuteration. This excess intensity appeared as a weak peak located at about $0.35 \AA^{-1}$ for neat DES comprising superstoichiometrical ethylene glycol. It appeared also during the gradual addition of water to the DES formed at the eutectic composition and shifted to smaller $Q\left(\sim 0.15 \AA^{-1}\right)$. Albeit being a small effect, this observation points to the segregation of ethylene glycol molecules. Supporting simulation studies, we suggest that the formation of strongly H-bonded ethylene glycol segregates is promoted by the higher affinity of water molecules with the ionic species, which therefore competes with the solvation of ions by ethylene glycol. We argue that the presence of ethylene glycol in excess with 
respect to the stoichiometry required to form DES supramolecular ionic complexes could have a similar effect. The latter situation calls for further investigation including simulation methods.

Unlike ethaline, aqueous solutions of a hydrophilic H-bonded nonionic mixture (lactic acid:glycerol) appeared homogeneously mixed at the mesoscopic scale. We infer that this is favored by the marginal amphiphilic nature of the molecules (comprising small alkyl groups) that limits the microsegregation of polar and apolar groups. Moreover, the H-bonding functional groups of the two constituents are comparable, which implies that they interact likewise with one or the other H-bonded molecule.

For the hydrophobic DES (menthol:decanoic acid), molecular segregation was more obvious and it led to a significant low-angle additional scattering contribution. This coherent peak centered at $Q=0$ was best fitted by a model, which assumed the presence of diluted or weakly interacting spherical aggregates of one compound embedded in its counterpart. However, we demonstrated that the size of such micelle-like domains remain small, typically at the molecular scale. An alternative description in terms of shapeless concentration fluctuations modelled by the OrnsteinZernike theory cannot be definitively ruled out. However, there was no indication that the size of such precursors of a hypothetical phase separation extends to larger scale as a function of the composition, and variable temperature experiments would certainly be useful.

In conclusion, we have demonstrated that some DESs and their aqueous solutions highlights the formation of supramolecular structures. However, none of them indicated that strong deviations from homogeneous mixing occur on a spatial scale that exceeds significantly a few molecular sizes. This conclusion was demonstrated for a selection of prototypical systems, which belong to three different classes of solvents. Although they cannot be necessarily generalized to 
all categorized DESs systems, we consider that the conclusions from this work can help sorting the different properties including ionic and H-bonding interaction, microheterogeneity, nonideality, and incomplete mixing, which could be considered as salient characters of DESs or rather considered as system specific, with the aim to convert them into useful functionality.

\section{Acknowledgments}

Support from Rennes Metropole and Europe (FEDER Fund - CPER PRINT2 TAN), and the ANR (Project NanoLiquids $N^{\circ}$ ANR-18-CE92-0011-01) is expressly acknowledged. This work is part of the $\mathrm{PhD}$ thesis of A.J. who benefits from a grant from the French Ministry of Higher Education, Research, and Innovation. The authors are grateful to the CNRS - network SolVATE (GDR 2035) for financial support and fruitful discussions.

\section{Supporting Information}

Temperature effect on the neutron scattering intensity of ethaline DES. Comparison of the neutron scattering intensity of ethaline DES aqueous solutions for two different isotopic labelling and for all the studied water mass fractions. 


\section{References}

1. Abbott, A.; Capper, G.; Davies, D.; Rasheed, R.; Tambyrajah, V., Novel solvent properties of choline chloride/urea mixtures. Chem. Commun. 2003, (1), 70-71.

2. Abbott, A.; Boothby, D.; Capper, G.; Davies, D.; Rasheed, R., Deep eutectic solvents formed between choline chloride and carboxylic acids: Versatile alternatives to ionic liquids. $J$. Am. Chem. Soc. 2004, 126 (29), 9142-9147.

3. Zhang, Q.; Vigier, K.; Royer, S.; Jerome, F., Deep eutectic solvents: syntheses, properties and applications. Chem. Soc. Rev. 2012, 41 (21), 7108-7146.

4. Smith, E.; Abbott, A.; Ryder, K., Deep Eutectic Solvents (DESs) and Their Applications. Chem. Rev. 2014, 114 (21), 11060-11082.

5. Ge, X.; Gu, C.; Wang, X.; Tu, J., Deep eutectic solvents (DESs)-derived advanced functional materials for energy and environmental applications: challenges, opportunities, and future vision. J. Mater. Chem. A 2017, 5 (18), 8209-8229.

6. Kollau, L.; Vis, M.; van den Bruinhorst, A.; Esteves, A.; Tuinier, R., Quantification of the liquid window of deep eutectic solvents. Chem. Commun. 2018, 54 (95), 13351-13354.

7. Martins, M.; Pinho, S.; Coutinho, J., Insights into the Nature of Eutectic and Deep Eutectic Mixtures. J. Solution Chem. 2019, 48 (7), 962-982.

8. Kaur, S.; Malik, A.; Kashyap, H. K., Anatomy of Microscopic Structure of Ethaline Deep Eutectic Solvent Decoded through Molecular Dynamics Simulations. J. Phys. Chem. B 2019, 123 (39), 8291-8299.

9. Kaur, S.; Gupta, A.; Kashyap, H. K., How Hydration Affects the Microscopic Structural Morphology in a Deep Eutectic Solvent. J. Phys. Chem. B 2020, 124 (11), 2230-2237. 
10. Hammond, O.; Bowron, D.; Edler, K., The Effect of Water upon Deep Eutectic Solvent Nanostructure: An Unusual Transition from Ionic Mixture to Aqueous Solution. Angew. Chem., Int. Ed. 2017, 56 (33), 9782-9785.

11. Passos, H.; Tavares, D.; Ferreira, A.; Freire, M.; Coutinho, J., Are Aqueous Biphasic Systems Composed of Deep Eutectic Solvents Ternary or Quaternary Systems? ACS Sustainable Chem. Eng. 2016, 4 (5), 2881-2886.

12. Dai, Y.; Witkamp, G.; Verpoorte, R.; Choi, Y., Tailoring properties of natural deep eutectic solvents with water to facilitate their applications. Food Chem. 2015, 187, 14-19.

13. Yadav, A.; Trivedi, S.; Rai, R.; Pandey, S., Densities and dynamic viscosities of (choline chloride plus glycerol) deep eutectic solvent and its aqueous mixtures in the temperature range (283.15-363.15) K. Fluid Phase Equilib. 2014, 367, 135-142.

14. Meng, X.; Ballerat-Busserolles, K.; Husson, P.; Andanson, J., Impact of water on the melting temperature of urea plus choline chloride deep eutectic solvent. New J. Chem. 2016, 40 (5), 4492-4499.

15. Ma, C.; Laaksonen, A.; Liu, C.; Lu, X.; Ji, X., The peculiar effect of water on ionic liquids and deep eutectic solvents. Chem. Soc. Rev. 2018, 47 (23), 8685-8720.

16. Kumari, P.; Shobhna; Kaur, S.; Kashyap, H., Influence of Hydration on the Structure of Reline Deep Eutectic Solvent: A Molecular Dynamics Study. ACS Omega 2018, 3 (11), 1524615255.

17. Lapena, D.; Lomba, L.; Artal, M.; Lafuente, C.; Giner, B., Thermophysical characterization of the deep eutectic solvent choline chloride:ethylene glycol and one of its mixtures with water. Fluid Phase Equilib. 2019, 492, 1-9. 
18. Posada, E.; Roldan-Ruiz, M.; Rioboo, R.; Gutierrez, M.; Ferrer, M.; del Monte, F., Nanophase separation in aqueous dilutions of a ternary DES as revealed by Brillouin and NMR spectroscopy. J. Mol. Liq. 2019, 276, 196-203.

19. Roldan-Ruiz, M.; Jimenez-Rioboo, R.; Gutierrez, M.; Ferrer, M.; del Monte, F., Brillouin and NMR spectroscopic studies of aqueous dilutions of malicine: Determining the dilution range for transition from a "water-in-DES" system to a "DES-in-water" one. J. Mol. Liq. 2019, 284, 175-181.

20. Ahmadi, R.; Hemmateenejad, B.; Safavi, A.; Shojaeifard, Z.; Shahsavar, A.; Mohajeri, A.; Dokoohaki, M. H.; Zolghadr, A. R., Deep eutectic-water binary solvent associations investigated by vibrational spectroscopy and chemometrics. Phys. Chem. Chem. Phys. 2018, 20 (27), 18463-18473.

21. Jani, A.; Sohier, T.; Morineau, D., Phase behavior of aqueous solutions of ethaline deep eutectic solvent. J. Mol. Liq. 2020, 304, 112701-112706.

22. Hammond, O.; Bowron, D.; Jackson, A.; Arnold, T.; Sanchez-Fernandez, A.; Tsapatsaris, N.; Sakai, V.; Edler, K., Resilience of Malic Acid Natural Deep Eutectic Solvent Nanostructure to Solidification and Hydration. J. Phys. Chem. B 2017, 121 (31), 7473-7483. 23. Hammond, O. S.; Bowron, D. T.; Edler, K. J., Liquid structure of the choline chlorideurea deep eutectic solvent (reline) from neutron diffraction and atomistic modelling. Green Chem. 2016, $18(9), 2736-2744$.

24. Gilmore, M.; Moura, L. M.; Turner, A. H.; Swadzba-Kwasny, M.; Callear, S. K.; McCune, J. A.; Scherman, O. A.; Holbrey, J. D., A comparison of choline: urea and choline: oxalic acid deep eutectic solvents at 338 K. J. Chem. Phys. 2018, 148 (19), 193823. 
25. Turner, A. H.; Holbrey, J. D., Investigation of glycerol hydrogen-bonding networks in choline chloride/glycerol eutectic-forming liquids using neutron diffraction. Phys. Chem. Chem. Phys. 2019, 21 (39), 21782-21789.

26. Hossain, S. S.; Samanta, A., How do the hydrocarbon chain length and hydroxyl group position influence the solute dynamics in alcohol-based deep eutectic solvents? Phys. Chem. Chem. Phys. 2018, 20 (38), 24613-24622.

27. Hossain, S. S.; Paul, S.; Samanta, A., Liquid Structure and Dynamics of Tetraalkylammonium Bromide-Based Deep Eutectic Solvents: Effect of Cation Chain Length. $J$. Phys. Chem. B 2019, 123 (31), 6842-6850.

28. Cui, Y. W.; Kuroda, D. G., Evidence of Molecular Heterogeneities in Amide-Based Deep Eutectic Solvents. J. Phys. Chem. A 2018, 122 (5), 1185-1193.

29. McDonald, S.; Murphy, T.; Imberti, S.; Warr, G. G.; Atkin, R., Amphiphilically Nanostructured Deep Eutectic Solvents. J. Phys. Chem. Lett. 2018, 9 (14), 3922-3927.

30. Alizadeh, V.; Geller, D.; Malberg, F.; Sanchez, P. B.; Padua, A.; Kirchner, B., Strong Microheterogeneity in Novel Deep Eutectic Solvents. ChemPhysChem 2019, 20 (14), 17861792.

31. Stefanovic, R.; Ludwig, M.; Webber, G. B.; Atkin, R.; Page, A. J., Nanostructure, hydrogen bonding and rheology in choline chloride deep eutectic solvents as a function of the hydrogen bond donor. Phys. Chem. Chem. Phys. 2017, 19 (4), 3297-3306.

32. López-Salas, N.; Vicent-Luna, J. M.; Posada, E.; Imberti, S.; Madero-Castro, R. M.; Calero, S.; Ania, C. O.; Jiménez-Riobóo, R. J.; Gutiérrez, M. C.; Ferrer, M. L.; del Monte, F., Further Extending the Dilution Range of the "Solvent-in-DES" Regime upon the Replacement of 
Water by an Organic Solvent with Hydrogen Bond Capabilities. ACS Sustainable Chem. Eng. 2020, 8 (32), 12120-12131.

33. Lopez-Salas, N.; Vicent-Luna, J. M.; Imberti, S.; Posada, E.; Roldan, M. J.; Anta, J. A.; Balestra, S. R. G.; Castro, R. M. M.; Calero, S.; Jimenez-Rioboo, R. J.; Gutierrez, M. C.; Ferrer, M. L.; del Monte, F., Looking at the "Water-in-Deep-Eutectic-Solvent" System: A Dilution Range for High Performance Eutectics. ACS Sustainable Chem. Eng. 2019, 7 (21), $17565-17573$.

34. Kaur, S.; Gupta, A.; Kashyap, H. K., Nanoscale Spatial Heterogeneity in Deep Eutectic Solvents. J. Phys. Chem. B 2016, 120 (27), 6712-6720.

35. Kaur, S.; Kashyap, H. K., Unusual Temperature Dependence of Nanoscale Structural Organization in Deep Eutectic Solvents. J. Phys. Chem. B 2018, 122 (20), 5242-5250.

36. Russina, O.; Lo Celso, F.; Plechkova, N.; Triolo, A., Emerging Evidences of Mesoscopic-Scale Complexity in Neat Ionic Liquids and Their Mixtures. J. Phys. Chem. Lett. 2017, 8 (6), 1197-1204.

37. Hamid, A. R. A.; Lefort, R.; Lechaux, Y.; Moreac, A.; Ghoufi, A.; Alba-Simionesco, C.; Morineau, D., Solvation Effects on Self-Association and Segregation Processes in tertButanol-Aprotic Solvent Binary Mixtures. J. Phys. Chem. B 2013, 117 (35), 10221-10230. 38. Kaur, S.; Sharma, S.; Kashyap, H. K., Bulk and interfacial structures of reline deep eutectic solvent: A molecular dynamics study. J. Chem. Phys. 2017, 147 (19), 194507.

39. Xiaobing, C.; Yaowen, C.; B., G. H.; G., K. D., Assessing the Location of Ionic and Molecular Solutes in a Molecularly Heterogeneous and Nonionic Deep Eutectic Solvent. J. Phys. Chem. B 2020, 124 (23), 4762-4773. 
40. Cui, Y. W.; Rushing, J. C.; Seifert, S.; Bedford, N. M.; Kuroda, D. G., Molecularly Heterogeneous Structure of a Nonionic Deep Eutectic Solvent Composed of N-Methylacetamide and Lauric Acid. J. Phys. Chem. B 2019, 123 (18), 3984-3993.

41. Weng, L. D.; Toner, M., Janus-faced role of water in defining nanostructure of choline chloride/glycerol deep eutectic solvent. Phys. Chem. Chem. Phys. 2018, 20 (35), 22455-22462. 42. Gontrani, L.; Bonomo, M.; Plechkova, N. V.; Dini, D.; Caminiti, R., X-Ray structure and ionic conductivity studies of anhydrous and hydrated choline chloride and oxalic acid deep eutectic solvents. Phys. Chem. Chem. Phys. 2018, 20 (48), 30120-30124.

43. Delso, I.; Lafuente, C.; Munoz-Embid, J.; Artal, M., NMR study of choline chloridebased deep eutectic solvents. J. Mol. Liq. 2019, 290, 111236.

44. Posada, E.; Lopez-Salas, N.; Rioboo, R. J. J.; Ferrer, M. L.; Gutierrez, M. C.; del Monte, F., Reline aqueous solutions behaving as liquid mixtures of H-bonded co-solvents: microphase segregation and formation of co-continuous structures as indicated by Brillouin and H-1 NMR spectroscopies. Phys. Chem. Chem. Phys. 2017, 19 (26), 17103-17110.

45. Kalhor, P.; Zheng, Y. Z.; Ashraf, H.; Cao, B. B.; Yu, Z. W., Influence of Hydration on the Structure and Interactions of Ethaline Deep-Eutectic Solvent: A Spectroscopic and Computational Study. ChemPhysChem 2020, 21 (10), 995-1005.

46. Mhanna, R.; Lefort, R.; Noirez, L.; Morineau, D., Microstructure and concentration fluctuations in alcohol-Toluene and alcohol-Cyclohexane binary liquids: A small angle neutron scattering study. J. Mol. Liq. 2016, 218, 198-207.

47. Garcia, G.; Aparicio, S.; Ullah, R.; Atilhan, M., Deep Eutectic Solvents: Physicochemical Properties and Gas Separation Applications. Energy Fuels 2015, 29 (4), 26162644. 
48. Hou, X. D.; Li, A. L.; Lin, K. P.; Wang, Y. Y.; Kuang, Z. Y.; Cao, S. L., Insight into the structure-function relationships of deep eutectic solvents during rice straw pretreatment. Bioresour. Technol. 2018, 249, 261-267.

49. Verma, R.; Mohan, M.; Goud, V. V.; Banerjee, T., Operational Strategies and Comprehensive Evaluation of Menthol Based Deep Eutectic Solvent for the Extraction of Lower Alcohols from Aqueous Media. ACS Sustainable Chem. Eng. 2018, 6 (12), 16920-16932.

50. Kaul, M. J.; Qadah, D.; Mandella, V.; Dietz, M. L., Systematic evaluation of hydrophobic deep-melting eutectics as alternative solvents for the extraction of organic solutes from aqueous solution. Rsc Adv. 2019, 9 (28), 15798-15804.

51. Shahbaz, K.; Mjalli Farouq, S.; Hashim, M.; ALNashef, I. M., Using Deep Eutectic Solvents for the Removal of Glycerol from Palm Oil-Based Biodiesel. J. Appl. Sci. 2010, 10, 3349-3354.

52. Lopez-Porfiri, P.; Brennecke, J.; Gonzalez-Miquel, M., Excess Molar Enthalpies of Deep Eutectic Solvents (DESs) Composed of Quaternary Ammonium Salts and Glycerol or Ethylene Glycol. J. Chem. Eng. Data 2016, 61 (12), 4245-4251.

53. Almasy, L.; Jancso, G., Small-angle neutron scattering and Kirkwood-Buff integral study of aqueous solutions of pyridine. J. Mol. Liq. 2004, 113 (1-3), 61-66.

54. Almasy, L.; Turmine, M.; Perera, A., Structure of aqueous solutions of ionic liquid 1butyl-3-methylimidazolium tetrafluoroborate by small-angle neutron scattering. J. Phys. Chem. B 2008, $112(8), 2382-2387$.

55. Darrigo, G.; Teixeira, J., Small-angle neutron-scattering study of D2O alcohol-solutions. J. Chem. Soc., Faraday Trans. 1990, 86 (9), 1503-1509. 
56. D'Arrigo, G.; Giordano, R.; Teixeira, J., Small-angle neutron scattering studies of aqueous solutions of short-chain amphiphiles. Eur. Phys. J. E: Soft Matter Biol. Phys.2003, 10 (2), 135-142.

57. Marczak, W.; Czech, B.; Almasy, L.; Lairez, D., Molecular clusters in aqueous solutions of pyridine and its methyl derivatives. Phys. Chem. Chem. Phys. 2011, 13 (13), 62606269.

58. Schroer, W.; Triolo, A.; Russina, O., Nature of Mesoscopic Organization in Protic Ionic Liquid-Alcohol Mixtures. J. Phys. Chem. B 2016, 120 (9), 2638-2643. 